\title{
A phase II study of docetaxel and vinorelbine plus filgrastim for HER-2 negative, stage IV breast cancer: SWOG S0102
}

\author{
Julie R. Gralow • William E. Barlow $\cdot$ Danika Lew $\cdot$ Kim Dammann • \\ George Somlo • Kristine J. Rinn · Stanley J. Vogel • Lucas Wong • \\ Robert B. Livingston - Gabriel N. Hortobagyi
}

Received: 25 August 2013/Accepted: 26 November 2013/Published online: 19 December 2013

(C) The Author(s) 2013. This article is published with open access at Springerlink.com

\begin{abstract}
Docetaxel and vinorelbine have demonstrated Single-agent activity in breast cancer. Preclinical studies suggest potential synergy between these antitubulin chemotherapy agents. This study evaluates these drugs in combination in metastatic breast cancer. Taxane-naive patients with HER-2 negative, stage IV breast cancer without prior chemotherapy for metastatic disease, were eligible. Docetaxel $\left(60 \mathrm{mg} / \mathrm{m}^{2}\right)$ was given intravenously on Day 1, vinorelbine $\left(27.5 \mathrm{mg} / \mathrm{m}^{2}\right)$ intravenously on Days 8 and 15 , and filgrastim on Days 2-21 of a 21-day cycle. The primary study outcome was one-year overall survival (OS), with secondary outcomes of progression-free survival (PFS), response rate (RR), and toxicity. Of 95 patients registered, 92 were eligible and received treatment. Oneyear OS was $74 \%$ (95\% CI 64-82\%) with a median OS of 22.3 months (95\% CI 18.8-31.4 months). One-year PFS was $34 \%$ (95\% CI 24-43\%) with median of 7.2 months (95\% CI 6.4-10.3). OS at 2 and 3 years were
\end{abstract}

Presented in part at the annual meeting of the American Society of Clinical Oncology, May-June 2005. Clinicaltrials.gov identifier: NCT00015938.

J. R. Gralow $(\bowtie) \cdot$ K. Dammann

University of Washington School of Medicine/Seattle Cancer

Care Alliance, 825 Eastlake Avenue East, G3-630, Seattle,

WA 98109, USA

e-mail: pink@u.washington.edu

W. E. Barlow · D. Lew

Southwest Oncology Group Statistical Center, Seattle, WA, USA

G. Somlo

City of Hope, Duarte, CA, USA

K. J. Rinn

Puget Sound Oncology Consortium, Swedish Cancer Institute,

Seattle, WA, USA
$49 \%$ (95\% CI $38-59 \%)$ and $30 \%$ (95\% CI $21-40 \%)$, respectively. OS was poorer for women with estrogenreceptor negative disease $(n=32)$ compared to estrogenreceptor positive $(n=60)(\log$-rank $p=0.031)$, but PFS was not significantly different $(p=0.11)$. RR was $59 \%$ among the 74 patients with measurable disease. Grade 3 and 4 adverse events were 48 and $16 \%$, respectively. Grade 4 neutropenia was $12 \%$ and grade $3 / 4$ febrile neutropenia was $3 \%$. Common grade $3 / 4$ nonhematologic toxicities were fatigue $(14 \%)$, pneumonitis $(10 \%)$, and dyspnea $(9 \%)$. The combination of docetaxel and vinorelbine is an active first-line chemotherapy in HER-2 nonoverexpressing, metastatic breast cancer. This combination is associated with significant hematologic and nonhematologic toxicity. The safety profile and expense of the filgrastim limit recommendations for routine use.

Keywords Breast cancer · Vinorelbine - Docetaxel · Metastatic

\author{
S. J. Vogel \\ University of Kansas, Kansas City, KS, USA \\ L. Wong \\ Scott and White Clinic, Temple, TX, USA \\ R. B. Livingston \\ University of Arizona, Tucson, AZ, USA \\ G. N. Hortobagyi \\ The University of Texas M. D. Anderson Cancer Center, \\ Houston, TX, USA
}




\section{Introduction}

Systemic therapy can decrease tumor burden, palliate symptoms, and lengthen survival in metastatic breast cancer, but is rarely curative. The search for better therapy includes identification of new agents and optimization of established drugs through improved delivery regimens, routes, and combinations.

The taxanes, paclitaxel and docetaxel, bind reversibly and specifically to the $\beta$-subunit of the mitotic spindle and promote microtubule polymerization [1]. Polymerized microtubules are quite stable, resulting in inhibition of reorganization of the microtubule network, and blocking cells in the G2-M phase of the cell cycle. Vinorelbine is a semisynthetic vinca alkaloid that inhibits microtubule assembly, interferes with formation of the mitotic spindle, and prevents cell division. Hence, the mechanism of action of taxanes and vinca alkaloids is complementary.

Investigation into the combined use of docetaxel and vinorelbine is supported by synergy shown in preclinical models. Drug-resistant cell lines produced by prolonged exposure to paclitaxel have "tubulin mutant" subunits which have an inherently slow rate of microtubule assembly, and increased sensitivity to vincas [2, 3]. Synergy of docetaxel and vinorelbine has been observed in solid tumors in transgenic mouse models [4].

Studies of docetaxel and vinorelbine in metastatic breast cancer have demonstrated activity of both drugs as single agents and in combination. Docetaxel is commonly given at doses of $60-100 \mathrm{mg} / \mathrm{m}^{2}$ every 3 weeks. In first-line metastatic breast cancer, docetaxel has response rates (RRs) of 50-68\% [5-8]. RRs of 34-57\% have been reported in anthracycline-resistant patients at $100 \mathrm{mg} / \mathrm{m}^{2}$ [9-11]. Overall RRs of $44 \%$ have been reported using $60 \mathrm{mg} / \mathrm{m}^{2}$. [12] The major dose-limiting toxicity of docetaxel is neutropenia, with grade 4 neutropenia occurring in $85-97 \%$ of patients receiving $100 \mathrm{mg} / \mathrm{m}^{2}$ [5-12].

Single-agent vinorelbine at doses of $25-30 \mathrm{mg} / \mathrm{m}^{2} /$ week shows RRs of 35-50 \% first-line and 32-35\% second-line in metastatic breast cancer [13-21]. There may be a doseresponse to this agent. A phase I-II trial of weekly vinorelbine with filgrastim achieved a median delivered dose intensity of $27.7 \mathrm{mg} / \mathrm{m}^{2} /$ week, with a $25 \% \mathrm{RR}$ in patients with prior taxane and anthracycline exposure [22].

Combinations of taxanes and vinca alkaloids have been studied in attempt to increase RR and survival. The University of Washington performed a trial of docetaxel $\left(60 \mathrm{mg} / \mathrm{m}^{2}\right.$ day 1$)$ and vinorelbine $\left(27.5 \mathrm{mg} / \mathrm{m}^{2}\right.$ days 8 and 15) plus filgrastim in 42 metastatic breast cancer patients, $42 \%$ of whom had received prior taxane [23]. Trastuzumab was allowed for HER-2 overexpressing tumors. The overall RR was $74 \%$, with median time to progression
(TTP) 6.8 months, and median overall survival (OS) of 30 months.

Based on Single-agent activity, noncross-reactivity, and potential synergy, SWOG tested docetaxel/vinorelbine as first-line chemotherapy in metastatic breast cancer. Filgrastim was added to maximize delivered dose intensity. Because of potential efficacy differences related to HER-2 status and HER-2 targeted therapy, two phase II trials were initiated. S0102, the subject of this report, enrolled HER-2 negative disease. S0215 added trastuzumab to the same chemotherapy regimen in HER-2 overexpressing tumors [24].

\section{Patients and methods}

The primary objective was to evaluate 1-year OS in HER-2 negative stage IV breast cancer patients. Secondary objectives included assessment of response, disease progression, and treatment-associated toxicity.

\section{Patient population}

Eligible patients were women aged $\geq 18$ with HER-2 nonoverexpressing, stage IV breast cancer. Evaluable and measurable disease was allowed. HER-2 status was determined by local immunohistochemistry or fluorescence in situ hybridization. Adjuvant chemotherapy was allowed if $>6$ months prior. Prior hormonal and radiation therapies were allowed in any setting. Prior taxane or vinca alkaloid was not permitted. Patients were required to have a Zubrod performance status of $0-2$, adequate hematologic values, and normal renal and liver function. Exclusions included central nervous system metastases, $\geq$ grade 2 motor or sensory peripheral neuropathy not due to cancer, sensitivity to E. Coli-derived proteins, or history of severe hypersensitivity reaction to polysorbate 80 . Patients completed written informed consent documenting that they understood the investigational nature of the study and would comply with study procedures.

\section{Study treatment}

Day 1 of each 21-day cycle patients received docetaxel $\left(60 \mathrm{mg} / \mathrm{m}^{2}\right)$ intravenously over $1-\mathrm{h}$. Beginning one day prior to docetaxel administration, patients received dexamethasone for a total of 3 days to reduce allergy and fluid retention. Filgrastim ( $5 \mu \mathrm{g} / \mathrm{kg} /$ day) was given subcutaneously days 2-21. Days 8 and 15 patients received vinorelbine $\left(27.5 \mathrm{mg} / \mathrm{m}^{2}\right)$ intravenously over 6-10 min. Treatment was terminated for disease progression, unacceptable toxicity, delay of treatment for $>2$ weeks due to hematologic toxicity or $>3$ weeks due to other toxicity, physician decision, or patient withdrawal. 
Dose modification

If the absolute neutrophil count (ANC) was $<1,500 / \mathrm{mm}^{3}$ on the day of chemotherapy, chemotherapy was delayed for 1 week but filgrastim was continued. After 1 week, if the ANC was $\geq 1,500 / \mathrm{mm}^{3}$, both docetaxel and vinorelbine were reduced permanently by $25 \%$ and treatment resumed. If ANC remained $<1,500 / \mathrm{mm}^{3}$, treatment was delayed for another week. If ANC was $\geq 1,500 / \mathrm{mm}^{3}$ after 2 weeks, docetaxel and vinorelbine were reduced by $25 \%$ and treatment resumed. If ANC continued $<1,500 / \mathrm{mm}^{3}$ at 2 weeks, the patient was removed from protocol. For neutropenic fever, both docetaxel and vinorelbine were reduced by $25 \%$.

Patients with platelet counts $<100,000 / \mathrm{mm}^{3}$ were suspended from treatment and rechecked at 1 and 2 weeks. If platelets returned to $\geq 100,000 / \mathrm{mm}^{3}$, treatment resumed with $25 \%$ dose reduction in both drugs. If platelets continued $<100,000 / \mathrm{mm}^{3}$ at 2 weeks, patients were removed from study.

If patients developed $\geq$ grade 3 motor or sensory neuropathy, docetaxel and vinorelbine were delayed until recovery to grade $\leq 2$. For grade $\geq 2$ stomatitis, chemotherapy was delayed until grade $\leq 1$. If either condition persisted for 3 weeks, the patient was removed from protocol. If evidence of abnormal liver function, docetaxel was held up to 3 weeks until recovery and resumed with $25 \%$ dose reduction. Protocol treatment was terminated if no recovery was observed within 3 weeks. If grade 4 docetaxel hypersensitivity occurred, the patient was removed from protocol. Dose reductions were not made for docetaxel hypersensitivity or fluid retention.

\section{Study assessments}

Prior to study entry, clinical information and tumor assessment were completed. CBC/differential/platelets were evaluated at baseline and weekly thereafter. Serum creatinine, bilirubin, SGOT/SGPT, and alkaline phosphatase were assessed at the beginning of each 21-day cycle. Electrolytes were assessed at baseline and after 6 and 15 weeks of treatment. Toxicity was assessed after each cycle.

Radiologic scans were required at baseline and after three cycles ( 9 weeks), but could be performed more often. Response was measured by RECIST criteria and applied to measurable and nonmeasurable disease. A patient was considered a responder if there was confirmed or unconfirmed partial or complete response. Others were considered nonresponders. RECIST requires evaluation by the same technique, so patients evaluated by different methods were classified as nonresponders, since disease progression may contribute to choice of a different method of assessment or inability to assess disease.
Adverse events were recorded and graded using the standardized NCI common toxicity criteria version 2.0. Within each toxicity category the highest grade of toxicity was recorded for each patient.

\section{Statistical analysis}

The primary outcome was 1-year OS, defined as time from registration to death by any cause. A secondary outcome was progression-free survival (PFS), defined as time from registration to the earliest of death or disease progression. Patients known to be alive were censored at last follow-up. The Kaplan-Meier method was used to compute OS and PFS and log-rank tests used to compare patients by hormone-receptor status. The accrual goal was 90, allowing 1-year OS to be estimated within $11 \%$ with $95 \%$ confidence (2-sided). We did not prespecify expected OS to be obtained for the drug combination to be considered better than standard care. All individuals were included in analysis unless ineligible or did not receive study medication.

Table 1 Descriptive characteristics of evaluable patients enrolled in S0102 $(n=92)$

\begin{tabular}{|c|c|c|}
\hline Characteristic & Frequency & Percentage \\
\hline \multicolumn{3}{|l|}{ Age (range 30-88) } \\
\hline$<50$ & 26 & 28 \\
\hline $50-59$ & 34 & 37 \\
\hline $60-69$ & 19 & 21 \\
\hline $70-88$ & 13 & 14 \\
\hline \multicolumn{3}{|l|}{ Race/ethnicity } \\
\hline nonHispanic White & 73 & 79 \\
\hline Hispanic & 3 & 3 \\
\hline Black & 9 & 10 \\
\hline Asian/Pacific Islander & 6 & 7 \\
\hline Native American & 1 & 1 \\
\hline \multicolumn{3}{|l|}{ Estrogen receptor status } \\
\hline Positive & 60 & 65 \\
\hline Negative & 32 & 35 \\
\hline \multicolumn{3}{|l|}{ Prior adjuvant chemotherapy } \\
\hline None & 50 & 54 \\
\hline Anthracycline & 21 & 23 \\
\hline Non-anthracycline & 21 & 23 \\
\hline $\begin{array}{l}\text { Prior hormonal therapy (adjuvant or } \\
\text { metastatic) }\end{array}$ & 51 & 55 \\
\hline \multicolumn{3}{|l|}{ Number of metastatic sites } \\
\hline$<3$ & 58 & 63 \\
\hline$\geq 3$ & 34 & 37 \\
\hline \multicolumn{3}{|l|}{ Measurable disease } \\
\hline Yes & 74 & 80 \\
\hline No & 18 & 20 \\
\hline
\end{tabular}



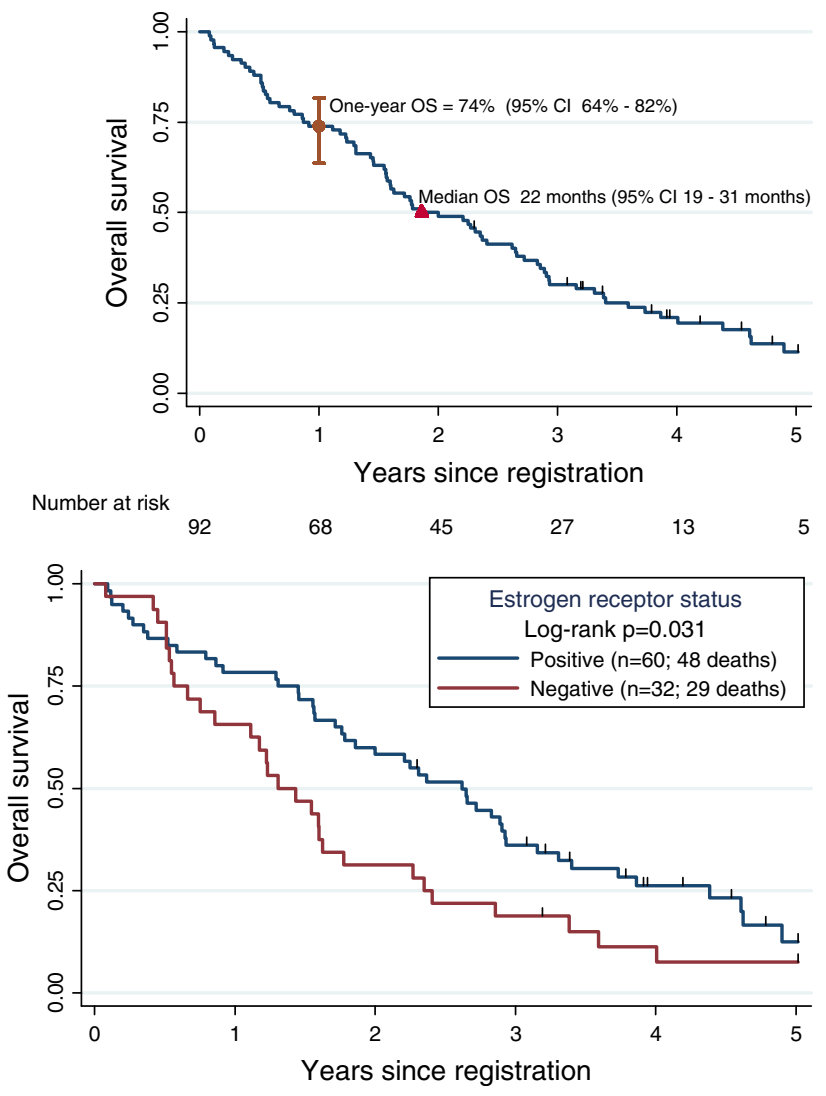

Fig. 1 Overall survival in S0102. a $n=92 ; 77$ deaths. b By estrogen-receptor status

\section{Results}

\section{Patient Population}

Between May 2001 to January 2004, 95 patients enrolled at 36 institutions. Two patients who did not have disease assessment during the proper time frame were ineligible. One additional patient did not receive treatment and was not evaluable. Of the remaining 92 eligible patients, two did not have toxicity assessments performed, so 90 patients were included in toxicity evaluation. Patient characteristics are summarized in Table 1. Patients ranged in age from 30 to 88 with a median of 56.5 years. Seventeen percent were nonwhite, and $3 \%$ had Hispanic ethnicity. Sixty-five percent had ER-positive tumors. All were HER-2 nonoverexpressing. Fifty-five percent received prior hormonal therapy in the adjuvant or metastatic setting. Forty-six percent had adjuvant chemotherapy, approximately half included anthracycline. Eighty percent of patients had measureable disease, $37 \%$ with $\geq 3$ metastatic sites.

No patients are on protocol treatment at the current time although three patients who have not progressed remain under observation more than 8 years after trial registration. The primary reason for going off treatment was progression
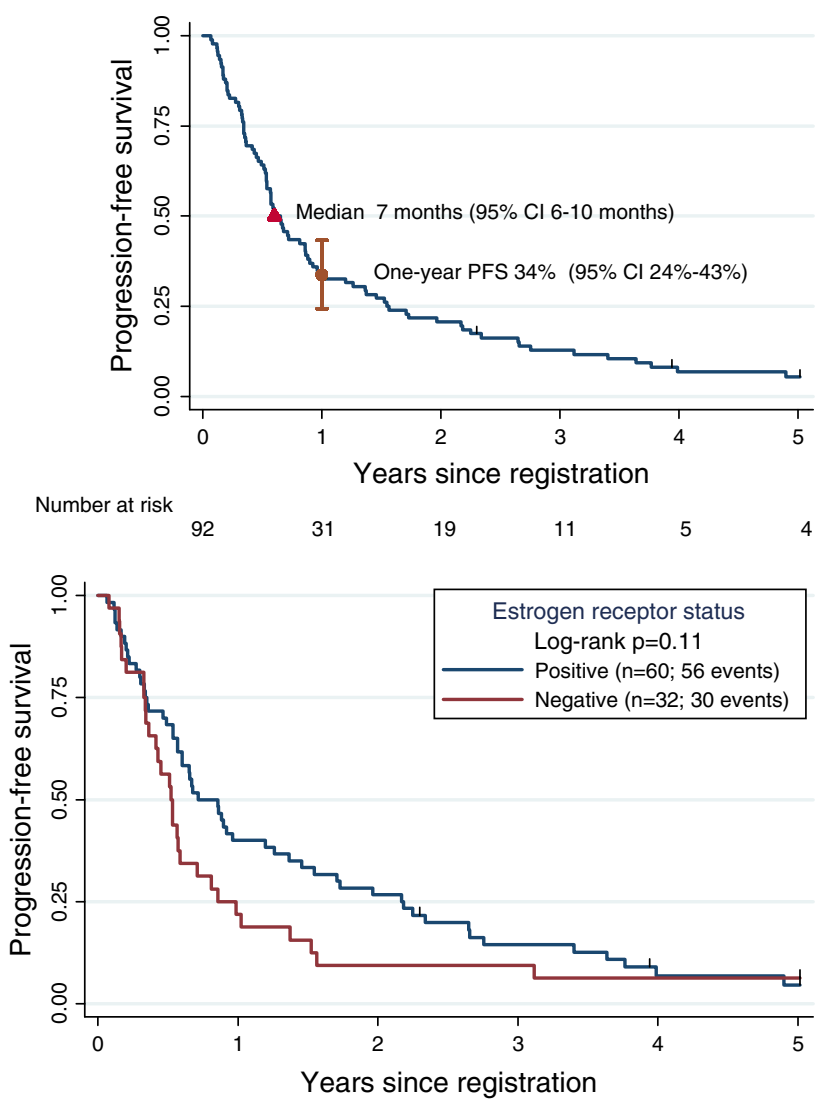

Fig. 2 Progression-free survival in S0102. a $n=92 ; 86$ events. b By estrogen-receptor status

or death (43\%). The remaining reasons were adverse events $(27 \%)$, refusal not due to adverse events (15\%), and other unspecified reasons $(14 \%)$.

Treatment outcomes

Of the 92 patients, 77 had died by 5 years. Figure 1 shows the Kaplan-Meier plot of OS. OS at 1-year was $74 \%(95 \%$ CI 64-82 \%), $49 \%$ (95\% CI 38-59\%) at 2-years, and $30 \%$ (95\% CI 21-40\%) at 3-years. Median OS was 22.3 months (95\% CI 18.8-31.4 months). Women with ER-positive disease had longer OS than those with ER-negative disease (log-rank $p=0.031$ ) (Fig. 1b). Median OS for the 60 women with ER-positive disease was 31.4 months (95\% CI 21.1-35.0 months) versus 15.7 months for ER-negative disease (95\% CI 9.0-21.3 months).

Of the 92 patients, 86 have progressed or died (Fig. 2). One-year PFS was $34 \%$ (95\% CI 24-43\%), 2-year PFS was $21 \%$ (95\% CI 13-29\%), and 3-year PFS was $13 \%$ (95\% CI 7-21\%). Median PFS was 7.2 months (95\% CI 6.4-10.3 months). Women with ER-positive disease had slightly longer PFS than those with ER-negative disease, though it was not statistically significant (log-rank $p=0.11$ ) (Fig. 2b). Since patients continued on treatment 
until progression or death, the median duration of treatment was approximately the same as median PFS. For the three off-protocol treatment patients who remain under observation without progression, two have hormone receptornegative tumors. We did not capture subsequent treatment information after going off-protocol treatment.

Table 2 shows the distribution of responses for the 74 women with measurable disease. There were 44 complete or partial (confirmed or unconfirmed) responses for a RR of $59 \%$ (95\% CI 47-71\%) (Table 2). RR did not differ significantly between ER-positive and ER-negative disease (Table 3; Fisher's exact $p=0.45$ ). Three patients were classified as not responding because different imaging techniques were used in response assessments.

\section{Safety}

Among the 90 patients evaluable for toxicity, adverse events possibly due to treatment were recorded for 135 different categories. The maximum degree experienced throughout treatment of each adverse event was recorded for each patient. Fourteen $(15.6 \%)$ patients reported grade 4 adverse events. Table 4 shows the most common adverse events, including all grade 4 events, and all toxicities with a combined grade $3 / 4$ score of $\geq 5 \%$.

Three patients $(3.3 \%)$ had fatal grade 5 events, rated as possibly treatment-related. One died of progressive respiratory failure following an admission for neutropenic fever and mucositis, and subsequent radiation to an endobronchial mass. Another died following admission for nonneutropenic sepsis and poorly controlled blood sugars. A third died of an acute cardiopulmonary event following

Table 2 Response to treatment $(N=92)$

\begin{tabular}{lcc}
\hline Response & Number & Percentage \\
\hline Complete response & 10 & 11 \\
Partial response & 35 & 38 \\
Stable/no response & 25 & 27 \\
Increasing disease & 15 & 16 \\
Early death & 1 & 1 \\
4Unable to assess & 6 & 7 \\
\hline
\end{tabular}

Table 3 Response to treatment by estrogen receptor status

\begin{tabular}{lccc}
\hline & ER positive & ER negative & $p$ value \\
\hline $\begin{array}{l}\text { One-year } \\
\text { survival }\end{array}$ & $78 \%(68-89 \%)$ & $66 \%(49-82 \%)$ & 0.007 \\
Median PFS & $\begin{array}{c}10.3 \text { months } \\
(6.8-14.4)\end{array}$ & $\begin{array}{c}6.4 \text { months } \\
(4.4-7.1)\end{array}$ & 0.07 \\
Response rate & $32 / 60(53 \%)$ & $\begin{array}{c}13 / 32(41 \%) \\
(24-59 \%)\end{array}$ & 0.28 \\
& $(40-66 \%)$ & & \\
\hline
\end{tabular}

Table 4 Adverse events possibly related to treatment $(N=90)$

\begin{tabular}{|c|c|c|c|}
\hline Adverse event & 3 & 4 & 5 \\
\hline Any adverse event & 43 & 14 & 3 \\
\hline \multicolumn{4}{|l|}{ Selected hematologic } \\
\hline Neutropenia/granulocytopenia & 12 & 11 & 0 \\
\hline Anemia & 16 & 0 & 0 \\
\hline Thrombocytopenia & 1 & 1 & 0 \\
\hline Leukopenia & 11 & 5 & 0 \\
\hline Infection with 3-4 neutropenia & 4 & 1 & 1 \\
\hline Febrile neutropenia & 2 & 1 & 0 \\
\hline PRBC transfusion & 6 & 0 & 0 \\
\hline \multicolumn{4}{|l|}{ Selected nonhematologic } \\
\hline Fatigue/malaise/lethargy & 13 & 0 & 0 \\
\hline Sensory neuropathy & 7 & 0 & 0 \\
\hline Hyperglycemia & 6 & 1 & 0 \\
\hline Stomatitis/pharyngitis & 3 & 2 & 0 \\
\hline Dyspnea & 5 & 3 & 0 \\
\hline Hypokalemia & 5 & 0 & 0 \\
\hline Anorexia & 3 & 1 & 0 \\
\hline Pneumonitis/infiltrates & 6 & 3 & 0 \\
\hline Bone pain & 6 & 0 & 0 \\
\hline Hypocalcemia & 4 & 1 & 0 \\
\hline Dehydration & 5 & 1 & 0 \\
\hline Respiratory infect w/neutropenia & 1 & 0 & 1 \\
\hline Respiratory infect w/o neutropenia & 0 & 0 & 1 \\
\hline Hypophosphatemia & 0 & 1 & 0 \\
\hline Hypoxia & 1 & 1 & 0 \\
\hline
\end{tabular}

admission for presumed community acquired pneumonia without cytopenia. All other deaths occurred after progression.

\section{Discussion}

The combination of docetaxel and vinorelbine with filgrastim, as studied in SWOG S0102, is active as first-line chemotherapy in HER-2 nonoverexpressing, metastatic breast cancer. We tested the docetaxel/vinorelbine combination based on potential synergy between these antitubulin agents suggested by preclinical studies. If chemotherapeutic agents with true synergy were identified, the case for combining drugs would be strengthened. While others have studied these agents in combination, the unique features of this study include the schedule of the drugs, the ability to achieve a high dose intensity due to the use of growth factor, and the inclusion of exclusively HER-2 nonoverexpressing breast cancers.

Several groups have studied combinations of the taxanes with other agents. In advanced breast cancer, combination chemotherapy regimens have demonstrated improved 
tumor RR, TTP, and prolonged survival when compared to single agents [25, 26]. Most trials have not tested the concurrent administration of two chemotherapy agents versus the same agents given as monotherapy in sequence. When combination chemotherapy regimens have been compared to sequential administration of the same agents, survival has not differed [27]. Combination chemotherapy, with a higher RR, is a reasonable option for some advanced breast cancer patients, particularly those with rapidly progressive, life-threatening disease.

Others have reported on combinations of docetaxel and vinorelbine in different schedules and doses in metastatic breast cancer. Most of these studies delivered the two drugs same day, without growth factor, which led to high RRs but also high toxicity [28-31]. Because of significant neutropenia seen in combining docetaxel and vinorelbine, subsequent studies incorporated growth factor to maintain dose intensity, but still included overlapping same-day dosing of the two drugs $[32,33]$. Despite the addition of filgrastim in these trials, neutropenia remained a common toxicity. Other common grade $3 / 4$ toxicities included fatigue, myalgias, and nail toxicities.

The response rate of $59 \%$ in S0102 was comparable to that reported in other docetaxel/vinorelbine trials, which ranged between 43 and $80 \%$ [28-33]. One-year OS, the primary study endpoint for S0102, was $74 \%$ in this multicenter, cooperative group trial. This endpoint is not reported in the other trials, and is, therefore, difficult to compare.

A unique feature of the S0102 regimen was the scheduling of drug administration on separate weeks, as well as the inclusion of growth factor support throughout. Myelosuppression was the primary toxicity, despite use of filgrastim. This study provides further data on the previously reported safety of same-day administration of vinorelbine and filgrastim [22].

A parallel study for patients with HER-2 overexpressing cancers, SWOG S0215, including the addition of trastuzumab to the S0102 docetaxel/vinorelbine regimen has been reported [24]. OS at 1-year in S0215 was $93 \%$, with a median of 40 months. One-year PFS was $70 \%$, with median PFS of 21 months. The RR was $66 \%$. Grade 4 toxicity was $19 \%$ and grade 3 was $33 \%$. Grade 4 neutropenia was $15 \%$. No deaths were attributed to treatment in S0215.

Given that S0102 excluded HER-2 overexpressing disease and accrued patients with relatively low prior anthracycline exposure and no prior taxane, it is difficult to find trials with similar populations for comparison. Docetaxel/capecitabine is an FDA approved combination chemotherapy regimen in metastatic breast cancer. Patients in the trial leading to its approval had anthracycline exposure, and up to three prior metastatic chemotherapy regimens [25]. The trial included cancers with a mix of HER-2 status. The RR was $42 \%$, TTP 6.1 months, median OS 14.5 months, and 1-year TTP $<20 \%$. Another approved combination taxane regimen in metastatic breast cancer is paclitaxel/gemcitabine [26]. This regimen was also studied in cancers with a mix of HER-2 expression. Patients had anthracycline exposure, no prior chemotherapy for metastatic disease, and no prior taxane or gemcitabine. The RR was $41.4 \%$, median PFS 5.9 months, median OS 18.6 months, and 1-year PFS $23 \%$. E2100, a trial of weekly paclitaxel \pm bevacizumab, is a taxane combination trial with a more similar patient population to S0102 [34]. The combination arm in E2100 was taxane plus a biologic and not chemotherapy. Patients in E2100 were essentially HER-2 negative, without prior chemotherapy for metastatic disease, but prior adjuvant chemotherapy, including taxane, was allowed if $>12$ months prior. This combination strategy showed superiority to Single-agent taxane in RR and PFS. The paclitaxel/bevacizumab arm reported a $36.9 \%$ RR, 11.8 month PFS, 26.7 month OS, and 1-year PFS of $50 \%$. Two-year PFS was $\sim 15 \%$. Tolerability of the combination arm was favorable compared to that reported for most taxane combination chemotherapy regimens.

Docetaxel and vinorelbine are active in combination in HER-2 nonoverexpressing, stage IV breast cancer. Both the efficacy and the toxicity of this combination may be schedule and dose dependent. The combination taxane/vinca regimen tested in S0102 is highly effective in first-line metastatic breast cancer, and may have a role in aggressive, rapidly progressive disease. However, safety concerns, including high rates of neutropenia despite the inclusion of filgrastim, as well as the expense of the filgrastim required with this regimen, limit recommendations for routine clinical use. For the majority of metastatic breast cancer patients, use of sequential Single-agent chemotherapies instead of combinations offers less side effects and improved quality of life. Combinations of chemotherapy agents and biologically targeted agents with reduced and/or nonoverlapping toxicities should be explored as a preferred strategy to improve antitumor efficacy and minimize the impact of therapy on patients' quality of life.

Acknowledgments The SWOG Breast Committee would like to thank all of the patients and clinicians who participated in this trial. This clinical trial was conducted by the Southwest Oncology Group Breast Cancer Committee, supported in part by the following PHS Cooperative Agreement grant numbers awarded by the National Cancer Institute, DHHS: CA32102, CA38926, CA46368, CA20319, CA74647, CA12644, CA58416, CA46282, CA04919, CA45377, CA67663, CA35281, CA63844, CA11083, CA35178, CA52654, CA45808, CA46441, CA14028, CA35431, CA67575, CA45560, CA58723, CA35090, CA35128, CA37981, CA27057, CA16385, CA35192, CA58861, and in part by Sanofi Aventis, Glaxo Smith Kline, Amgen, and the Breast Cancer Research Foundation. 
Conflict of interest Julie Gralow received research funding from Novartis, Amgen, Genentech and Roche. Lucas Wong serves in a consultancy/advisory role for Bristol Myers Squibb. Gabriel Hortobagyi researches research funding from Novartis, and serves in a consultancy/advisory role for AstraZeneca, Genentech, Novartis and Sanofi.

Open Access This article is distributed under the terms of the Creative Commons Attribution Noncommercial License which permits any noncommercial use, distribution, and reproduction in any medium, provided the original author(s) and the source are credited.

\section{References}

1. Schiff PB, Horwitz SB (1980) Taxol stabilizes microtubules in mouse fibroblast cells. Proc Natl Acad Sci USA 77:1561-1565

2. Cabral F, Wible L, Brenner S, Brinkley BR (1983) Taxolrequiring mutant of Chinese hamster ovary cells with impaired mitotic spindle activity. J Cell Biol 97:30-39

3. Zhan Z, Kang Y-K, Giannakakou P et al (1994) Tubulin expression and polymerization in normal tissues, human tumors and paclitaxel selected ovarian and breast cancer carcinoma cell lines. Proc Am Assoc Cancer Res 35:390

4. Bissery MC, Vrignaud P, Lavelle F (1995) Preclinical profile of docetaxel (taxotere): efficacy as a single agent and in combination. Semin Oncol 22(Suppl 13):3-16

5. Valero V (1997) Docetaxel as single-agent therapy in metastatic breast cancer: clinical efficacy. Semin Oncol 24:S13-18

6. Trudeau ME, Eisenhauer EA, Higgins BP, Letendre F, Lofters WS, Norris BD, Vandenberg TA, Delorme F, Muldal AM (1996) Docetaxel in patients with metastatic breast cancer: a phase II study of the National Cancer Institute of Canada-Clinical Trials Group. J Clin Oncol 14:422-428

7. Hudis CA, Seifman AD, Crown JP, Balmaceda C, Freilich R, Gilewski TA, Hakes TB, Currie V, Lebwohl DE, Baselga J, Raptis G, Gollub M, Robles M, Bruno R, Norton L (1996) Phase II and pharmacologic study of docetaxel as initial chemotherapy for metastatic breast cancer. J Clin Oncol 14:58-65

8. Fumoleau P, Chevallier B, Kerbat P, Krakowski Y, Misset JL, Maugard-Louboutin C, Dieras V, Azli N, Bougon N, Riva A, Roche H (1996) A multicentre phase II study of the efficacy and safety of docetaxel as first-line treatment of advanced breast cancer: report of the Clinical Screening Group of the EORTC. Ann Oncol 7:165-171

9. Valero V, Holmes FA, Walters RS, Theriault RL, Esparza L, Fraschini G, Fonseca GA, Bellet RE, Buzdar AU, Hortobagyi GN (1995) Phase II trial of docetaxel: a new, highly effective antineoplastic agent in the management of patients with anthracycline-resistant metastatic breast cancer. J Clin Oncol 13:2886-2894

10. Ravdin PM, Burris HA, Cook G, Eisenberg P, Kane M, Bierman WA, Mortimer J, Genevois E, Bellet RE (1995) Phase II trial of docetaxel in advanced anthracycline-resistant or anthracenedione-resistant breast cancer. J Clin Oncol 13:2879-2885

11. Ten-Bokkel-Huinink WW, Prove AM, Piccart M, Steward W, Tursz T, Wanders J, Franklin H, Clavel M, Verweij J, Alakl M (1994) A phase II trial with docetaxel (Taxotere) in second line treatment with chemotherapy for advanced breast cancer. A study of the EORTC Early Clinical Trials Group. Ann Oncol 5:527-532

12. Adachi I, Watanabe T, Takashima S, Narabayashi M, Horikoshi $\mathrm{N}$, Aoyama H, Taguchi T (1996) A late phase II study of RP56976 (docetaxel) in patients with advanced or recurrent breast cancer. Br J Cancer 73:210-216
13. Terenziani M, Demicheli R, Brambilla C, Ferrari L, Moliterni A, Zambetti M, Caraceni A, Martini C, Bonadonna G (1996) Vinorelbine: an active, non-cross resistant drug in advanced breast cancer. Results from a phase II study. Breast Cancer Res Treat 39:285-291

14. Weber BL, Vogel C, Jones S, Harvey H, Hutchins L, Bigley J, Hohneker J (1995) Intravenous vinorelbine as first-line and second-line therapy in advanced breast cancer. J Clin Oncol 13:2722-2730

15. Twelves CJ, Dobbs NA, Curnow A, Coleman RE, Stewart AL, Tyrrell CJ, Canney P, Rubens RD (1994) A phase II, multicentre, UK study of vinorelbine in advanced breast cancer. Br J Cancer 70:990-993

16. Fumoleau P, Delgado FM, Delozier T, Monnier A, Gil Delgado MA, Kerbrat P, Garcia-Giralt E, Keiling R, Namer M, Closon MT (1993) Phase II trial of weekly intravenous vinorelbine in first-line advanced breast cancer chemotherapy. J Clin Oncol 11:1245-1252

17. Canobbio L, Boccardo F, Pastorino G, Brema F, Martini C, Resasco M, Santi L (1989) Phase II study of vinorelbine in advanced breast cancer. Semin Oncol 16(Suppl 4):33-36

18. Garcia-Conde J, Lluch A, Martin M, Casado A, Gervasio H, De Oliveira C, De Pablo JL, Gorostiaga J, Girón GC, Cervantes A (1994) Phase II trial of weekly IV vinorelbine in first-line advanced breast cancer chemotherapy. Ann Oncol 5:854-857

19. Bruno S, Puerto VL, Mickiewicz E, Hegg R, Texeira LC, Gaitan L, Martinez L, Fernandez O, Otero J, Kesselring G (1995) Phase II trial of weekly i.v. vinorelbine as a single agent in first-line advanced breast cancer chemotherapy. The Latin American experience. Am J Clin Oncol 18:392-396

20. Jones S, Winer E, Vogel C, Laufman L, Hutchins L, O'Rourke M, Lembersky B, Budman D, Bigley J, Hohneker J (1995) Randomized comparison of vinorelbine and melphalan in anthracycline-refractory advanced breast cancer. J Clin Oncol $13: 2567-2574$

21. Gasparini G, Caffo O, Barni S, Frontini L, Testolin A, Guglielmi RB, Ambrosini G (1994) Vinorelbine is an active antiproliferative agent in pretreated advanced breast cancer patients: a phase II study. J Clin Oncol 12:2094-2101

22. Livingston RB, Ellis GK, Gralow JR, Williams MA, White R, McGuirt C, Adamkiewicz BB, Long CA (1997) Dose-intensive vinorelbine with concurrent granulocyte-colony-stimulating factor support in paclitaxel-refractory metastatic breast cancer. J Clin Oncol 15:1395-1400

23. Gralow JR, Ellis GK, Williams MA, Livingston RB (2000) Docetaxel and vinorelbine with concurrent G-CSF support: a phase II study in stage IV breast cancer. Proc Am Soc Clin Oncol (abstr 410) 19:160a

24. Livingston RB, Barlow WE, Kash JJ, Albain KS, Gralow JR, Lew DL, Flaherty LE, Royce ME, Hortobagyi GN (2011) SWOG S0215: a phase II study of docetaxel and vinorelbine plus filgrastim with weekly trastuzumab for HER2-positive, stage IV breast cancer. Breast Cancer Res Treat 130:123-131

25. O'Shaughnessy J, Miles D, Vukelja S, Moiseyenko V, Ayoub JP, Cervantes G, Fumoleau P, Jones S, Lui WY, Mauriac L, Twelves C, Van Hazel G, Verma S, Leonard R (2002) Superior survival with capecitabine plus docetaxel combination therapy in anthracycline-pretreated patients with advanced breast cancer: phase III trial results. J Clin Oncol 20:2812-2823

26. Albain KS, Nag SM, Calderillo-Ruiz G, Jordaan JP, Llombart AC, Pluzanska A, Rolski J, Melemed AS, Reyes-Vidal JM, Sekhon JS, Simms L, O'Shaughnessy J (2008) Gemcitabine plus paclitaxel versus paclitaxel monotherapy in patients with metastatic breast cancer and prior anthracycline treatment. J Clin Oncol 26:3950-3957 
27. Sledge GW, Neuberg D, Bernardo P, Ingle JN, Martino S, Rowinsky EK, Wood WC (2003) Phase III trial of doxorubicin, paclitaxel, and the combination of doxorubicin and paclitaxel as front-line chemotherapy for metastatic breast cancer: an intergroup trial (E1193). J Clin Oncol 21:588-592

28. Fumoleau P, F'ety R, Delecroix V, Perrocheau G, Azli N (1997) Docetaxel combined with vinorelbine: phase I results and new study designs. Oncology 11:29-31

29. Campone M, Blasinska-Morawiec M, Tekiela A, Koralewski P, Pouget JC, Douville I, Brandely (2009) Phase II study of vinorelbine (alternating intravenous and oral) in combination with docetaxel as first-line chemotherapy in metastatic breast cancer. Cancer Chemother Pharmacol 63:43-937

30. Savio G, Laudani A, Leonardi V, Pepe A, Scianna C, Gebbia V, Agostara B (2006) Treatment of metastatic breast cancer with vinorelbine and docetaxel. Am J Clin Oncol 29:276-280
31. Cals L, Nouyrigat P, Valenza B, Pedinelli FJ, Juin P (2004) Weekly combination of docetaxel and vinorelbine in metastatic breast cancer: a phase I/II study. Oncology 67:257-261

32. Gomez-Bernal A, Cruz JJ, Olaverri A, Arizcun A, Martín T, Rodríguez CA, Martín G, Fonseca E, Sánchez P (2005) Biweekly docetaxel and vinorelbine with granulocyte-colony stimulating factor support for patients with anthracycline-resistant metastatic breast cancer. Anticancer Drugs 16:77-82

33. Ibrahim NK, Rahman Z, Valero V, Murray JL 3rd, Frye D, Hortobagyi GN (2002) Phase I study of vinorelbine and docetaxel with granulocyte colony-stimulating factor support in the treatment of metastatic breast cancer. Cancer Invest 20:29-37

34. Miller K, Wang M, Gralow J, Dickler M, Cobleigh M, Perez EA, Shenkier T, Cella D, Davidson NE (2007) Paclitaxel plus bevacizumab versus paclitaxel alone for metastatic breast cancer. N Engl J Med 357:2666-2676 